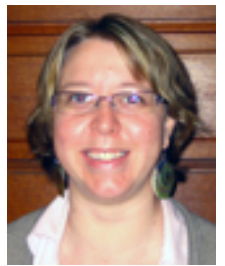

\title{
On Editing and APA Style for ILI at AEC
}

Greetings! As Issues for Language Instruction at the AEC launches its second volume, we would like to publish our submission guidelines. The purpose of doing this is to ensure a consistent look and style with the goal of elevating the professionalism of our journal.

With this idea in mind, we have chosen the American Psychological Association or APA Style for this journal. The APA style is commonly used by journals in our field, including TESOL Quarterly. If you, however, are not familiar with APA Style, please do not let that deter you from submitting something! At the end of this editor's note, and in the ILI folder on the shared drive, I have provided a quick “cheat sheet” on the basic aspects of APA style.

Additionally, I am always on hand to answer any questions you might have. If however you cannot find me, submit anyway! We are looking for your perspectives, not your ability to conform to a certain style.

Finally, we would like to briefly discuss our editing process. All submissions are first reviewed by Marcellino who edits for content related issues. Articles are then given to Elizabeth for copy editing. We both use the track changes function in Word. When we send edited articles back to you we ask that you accept or deny the track changes. To do this, see the steps below:

1. Click on the "Review" Tab in Word.

2. Look at the box labeled "Changes" towards the right hand side of the toolbar.

3. There are two buttons labeled "Accept" and "Reject".

4. If you click one of the buttons itself, it will automatically do what you ask and move to the next change. If you want more control, you may click the little down arrow under each box and choose your preferred command.

Doing this makes our editing process much simpler and it gets rid of all those ugly little lines that are all over your paper! As with APA style questions, Marcellino and I are always happy to answer questions about this process.

So without further ado, see the cheat sheet below and start writing! We look forward to your submissions.

Elizabeth Gould,

Copy Editor 


\section{APA Cheat Sheet}

The ILI editors have decided to standardize our formatting parameters by using APA style. We would appreciate it if you could try to follow this format when writing your articles. If you are unfamiliar with the rules of APA style, feel free to submit anyway. We value content over format. This cheat sheet provides an easy-to-read guide for the basics of citing and referencing sources. If you have more complicated styling issues, feel free to chat with Elizabeth!

\section{In-Text Citing:}

\section{Direct Quote (books and articles):}

"The inadequacy of a strictly bottom-up approach has been demonstrated by research that shows that we do not store listening texts word-for-word as suggested by the bottom-up approach” (Nunan, 1999, p. 202).

\section{Parentheses:}

after quotation marks

but before period.

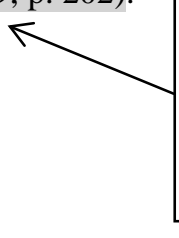

Author/Date/Location: Last name, date published, page number

OR

According to Nunan (1999), "the inadequacy of a strictly bottom-up approach has been demonstrated by research that shows that we do not store listening texts word-for-word as suggested by the bottom-up approach” (p. 202).

\section{Indirect Quote (books and articles):}

One of the drawbacks of the bottom-up approach is that it doesn't take into account that we do not hold texts word-for-word in our memories (Nunan, 1999).

OR

According to Nunan (1999), one of the drawbacks of the bottom-up approach is that it doesn't take into account that we do not hold texts word-for-word in our memories.

\section{Direct or indirect quotes with more than one author:}

According to Nunan and Vygostsky (1999)....

OR

....we do not hold texts word-for-word in our memories (Nunan \& Vygotsky, 1999).

\section{References:}

\section{Book:}

Nunan, D. (1999). Second language teaching \& learning. Boston: Heinle \& Heinle Publishers.
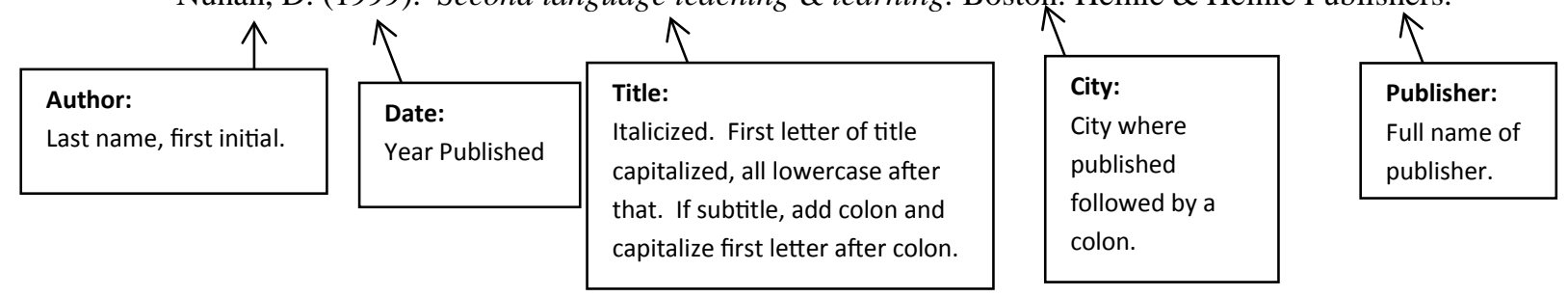


\section{Journal Article:}

Hinkel, E. (2006). Current perspectives on teaching the four skills. TESOL Quarterly, 40(1), 109-131.

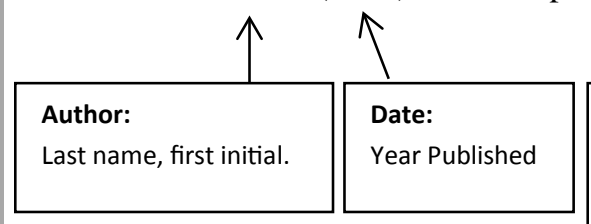

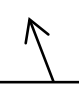

Title:

First letter of title capitalized, all lowercase after that. If subtitle, add colon and capitalize first letter after colon.

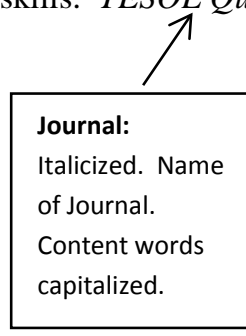

Journal:

talicized. Name

f Journal.

capitalized.

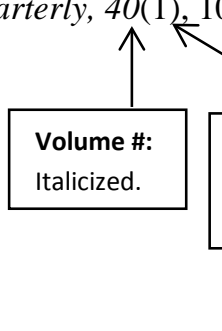

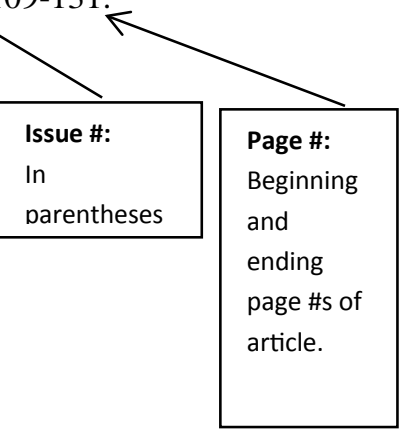

More than one author (books and journals):

Nunan, D. \& Vygotsky, I. (1999). The rest of reference is the same.

Nunan D., Vygotsky, I., \& Krashen, S. (1999). The rest of reference is the same.

\section{Headings:}

Title: Centered, Bold and Upper and Lowercase

\section{$1^{\text {st }}$ Heading: Flush Left, Bold, Upper and Lowercase}

$2^{\text {nd }}$ Heading: Flush Left, Italics, Upper and Lowercase

$3^{\text {rd }}$ Heading: Bold, Within Paragraph

$4^{\text {th }}$ Heading: Italics Within Paragraph 